\title{
Cost-effectiveness of the 13-valent Pneumococcal Conjugate Vaccine in Children in Portugal
}

\author{
Miguel Gouveia, PhD, * Francesca Fiorentino, MSc, † Gonçalo Jesus, PharmD, † João Costa, PhD, †ł \\ and Margarida Borges, MD†t
}

Background : Pneumococcal infections are the leading cause of vaccinepreventable death in children. In June 2015, the 13-valent pneumococcal conjugate vaccine (PCV13) was introduced in the Portuguese Immunization Program. We evaluated the cost-effectiveness of children vaccinated with PCV13 versus no vaccination for preventing pneumococcal diseases.

Methods: A cohort simulation model for 2014 Portuguese newborns was used, considering a lifetime horizon and existence of herd effect on adults. Model outcomes measured life years gained, direct and indirect healthcare costs and net benefits considering $€ 20,000$ per life years gained. PCV13 clinical effectiveness rate by serotype covered was assumed similar to PCV7. Patients' resource use was based on 2014 diagnostic-related group database and experts' opinion, while national legislation and official drug cost database were the main sources for unitary costs. Univariate sensitivity analyses were conducted to assess results' effectiveness.

Results: In base case scenario, PCV13 was a dominant strategy, being associated with better health outcomes and lower costs. In a lifetime, a total of 6238 infections (excluding acute otitis media) and 130 deaths were averted, with a total saving of $€ 397,217$ ( $\$ 432,966)$. Net benefits were estimated above $€ 28$ million ( $\$ 30$ million). Results were robust in all sensitivity analyses, with positive net benefits, except when herd effect was excluded. Conclusions: Vaccination of children with PCV13 starting in their first year of life is a cost-effective intervention with the potential to save costs to the Portuguese health system and to provide health gains by reducing the burden of pneumococcal disease in the vaccines and through the herd effect of this vaccine.

Key Words: pneumococcal infections, 13-valent pneumococcal vaccine, cost-benefit analysis

(Pediatr Infect Dis J 2017;36:782-787)

Dn eumococcal disease (PD) is caused by Streptococcus pneumoniae, a bacterium responsible for a large spectrum of infections which can be classified into invasive (eg, septicemia and meningitis) or noninvasive (eg, pneumonia without bacteremia and pleural effu-

Accepted for publication March 8, 2017.

From the *Católica Lisbon School of Business and Economics, Universidade Católica Portuguesa, Lisboa, Portugal; †Centro de Estudos de Medicina Baseada na Evidência, Faculdade de Medicina da, Universidade de Lisboa, Lisboa, Portugal; \$Laboratório de Farmacologia Clínica e Terapêutica, Faculdade de Medicina da Universidade de Lisboa, Lisboa, Portugal; §Unidade de Farmacologia Clínica, Instituto de Medicina Molecular, Lisboa, Portugal; and Unidade de Farmacologia Clínica, Centro Hospitalar Lisboa Central EPE, Lisboa, Portugal.

This study was funded by Pfizer Biofarmacêutica, Sociedade Unipessoal Lda. Funding was independent of the study outcome.

M.G. has served as a speaker and consultant for MSD Portugal, Bristol-Myers Squibb Farmacêutica Portuguesa, Laboratórios Pfizer. He has been an advisory board member for Grünenthal Portugal. All these activity-concerned areas are not related to this work.

Address for correspondence: Miguel Gouveia, PhD, Católica Lisbon School of Business and Economics, Palma de Cima, 1649-023 Lisboa, Portugal. E-mail:mig@ucp.pt.

Copyright (C) 2017 Wolters Kluwer Health, Inc. All rights reserved.

ISSN: $0891-3668 / 17 / 3608-0782$

DOI: $10.1097 /$ INF.0000000000001587 sion) PD. ${ }^{1}$ PD is most common in young children and among the elderly. ${ }^{2}$ Pneumococcal infections are the leading cause of vaccinepreventable death in children and are estimated to cause about $5.5 \%$ of the annual 8.8 million deaths among children $<5$ years of age. ${ }^{1}$

Most cases $(83 \%)$ of pneumococcal meningitis among children 0-59 months of age occurred below the age of 2 years. ${ }^{3}$ In Portugal, data from a recent prospective study of pediatric patients found that $48 \%$ of invasive PD (IPD) cases occur in children less than 2 years of age and $31 \%$ occur in children during their first year of life. ${ }^{4}$

Despite the use of antibiotics, PD remains an important and burdensome disease, suggesting that vaccination is likely to be one of the interventions with the most significant impact on the incidence of pneumococcal pneumonia (PP) and IPD, as highlighted by the World Health Organization. ${ }^{5}$ Evidence exists that the introduction of vaccines to be used among children has the potential to reduce the incidence of IPD, even in groups (eg, adults) not primarily targeted by the immunization program. ${ }^{1}$ This is due, at least partially, to a herd protection effect. In fact, infants and young children are thought to be the main reservoir of this agent.

The 13-valent pneumococcal conjugate vaccine (PCV13) is indicated for the prevention of invasive disease, pneumonia and acute otitis media (AOM) caused by S. pneumoniae in children $(<18$ years of age) and in adults (except for AOM). Recently (June 2015), PCV13 has been included in the Portuguese National Vaccination Plan. ${ }^{6}$ Two 2015 guidelines from the National Directorate General of Health define the age and risk groups for IPD for which PCV13 is recommended. Besides the inclusion of PCV13 in the Portuguese National Vaccination Plan for children born from January 1, 2015, PCV13 is recommended and free of charge for children ( $<18$ years) with increased risk of IPD. ${ }^{7,8}$

In this context, it is relevant to estimate for Portugal, the cost-effectiveness of PCV13 in the prevention of pneumonia and IPD in children, in comparison with the effect of "no vaccination."

\section{MATERIALS AND METHODS}

\section{Model Structure}

A cohort simulation model developed by the authors was used to estimate the number of infections and deaths averted by children vaccinated with PCV13, life years gained (LYG) and costeffectiveness ratios.

A cohort of 100,000 newborns is simulated in a lifetime horizon in 2 different scenarios: (1) all children vaccinated with PCV13 (using a vaccination scheme with 2 doses given in the first year of life and a booster dose in the following year) and (2) no vaccination. As illustrated in Figure 1, in each period (annual cycles), individuals have a probability of contracting IPD, PP and AOM. The disease episodes may result in death, long-lasting disease sequelae (in case of meningitis) or complete health recovery. Death may also occur from other causes not related to PD.

The analysis considers a lifetime horizon to capture the vaccination benefits in adult age (when infections may still occur) and also because meningitis sequelae are considered to be permanent. The results are presented for the Portuguese cohort of newborns in 2014. ${ }^{9}$ As recommended by the Portuguese Authority of Medicines 


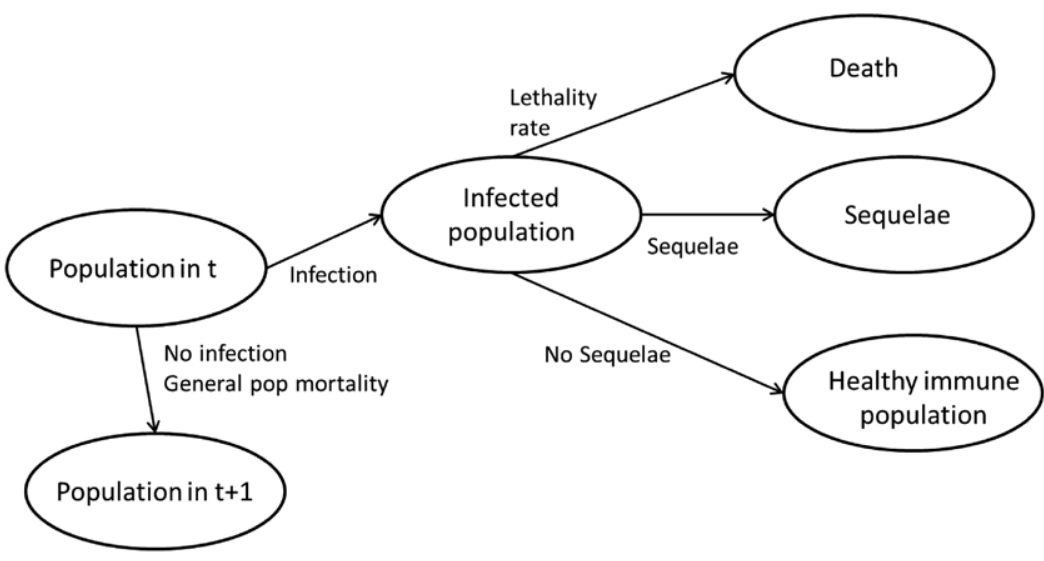

FIGURE 1. Scheme of model structure.

$t$ : time-period; pop: population

and Health Products (INFARMED) guidelines, ${ }^{10}$ benefits and costs were discounted at a $5 \%$ rate, and a societal perspective was adopted.

\section{Epidemiologic Parameters Incidence Rates}

Epidemiologic parameters needed to be calibrated for both children and adults. Information regarding adults is relevant for 2 reasons: (1) the model considers a lifetime horizon and (2) a "herd effect" of children vaccination is included, that is, children vaccination results in a positive externality, reducing the incidence of PD in adults.

For the purpose of this study, we considered their estimates for IPD incidence ${ }^{4}$ and for long-term sequelae in children surviving a meningitis episode $\left(25.5 \%\right.$; data between 1991 and 2001), ${ }^{11}$ but not for PP incidence. We considered that the Invasive Pneumococcal Disease Study Group from the Portuguese Pediatric Infectious Disease Society's estimation for inpatient PP incidence rates $(2.57 / 100)$ represented a substantial underestimation, as it was only $3.5 \%$ of the incidence rate $(72.53 / 100)$ estimated using the 2014 National Diagnosis Related Groups (DRG) database. ${ }^{12}$

Because of the large number of pneumonia episodes without an identified agent in the DRG database, ${ }^{12} 2$ assumptions were made: (1) the proportion of bacterial infections in pneumonia without identified agent equals the proportion of bacterial infections in pneumonia with identified agent $(56 \%)$ and (2) the proportion of PP in bacterial pneumonia cases without identified agent equals the ratio between pneumococcal bacterial cases and all bacterial cases with identified agent $(60.7 \%)$.

Because of lack of national data for overall AOM incidence, the model was calibrated with the Spanish values reported by Liese et al, ${ }^{13}$ based on cases diagnosed by physicians during a 12-month prospective study in children $0-5$ years of age. The incidence rates of AOM estimated for Spain times the Portuguese pediatric populations yield the total number of AOM cases. The proportion of inpatient episodes in the total number of AOM cases was computed as the ratio between the number of episodes in the DRG database ${ }^{12}$ with AOM and total number of AOM cases. According to this computation, $0.13 \%$ of all AOM cases correspond to inpatient episodes.

Adult PD incidence rates were estimated based on the DRG database ${ }^{12}$ for 3 age groups: $18-44,45-64$ and $65+$ years. The methodology for estimating inpatient PP incidence in adults was identical to the methodology used for PP incidence in pediatric ages. Similarly, in the case of IPD (sepsis and meningitis), the proportion of PD in the group of invasive infections without an identified agent was assumed to be the same as in episodes with identified agent. Incidence of pneumococcal bacteremia in adults was assumed to be zero.

Outpatient pneumococcal episodes were assumed to be $7: 3$ of the inpatient episodes, a ratio consistent with the results presented by Froes. ${ }^{14}$

Incidence estimates described above fail to represent incidence in the "no vaccination" scenario, because the current rates reflect a reality where the majority of children and a proportion of adults have already been vaccinated. Therefore, the incidence rate in the baseline scenario was estimated by adjusting the current incidence rate taking into account vaccination coverage, serotype coverage, vaccine efficacy and herd effect (for the adult population). Vaccination coverage rates in children and adults were considered to be $60.8 \%$ and $0.6 \%$, respectively, based on data from vaccination sales (Pfizer, Lda; 2016).

\section{Lethality Rates}

For children, a $1.7 \%$ lethality rate was considered for IPD 4 and assumed to be the same for PP.

For adults, PD lethality rates were estimated from the DRG database: ${ }^{12}$ deaths in episodes whose main diagnosis was pneumococcal meningitis (ICD-9-CM 320.1), pneumococcal septicemia (ICD-9-CM 038.2) and PP (ICD-9-CM 481) were included.

Portugal general population mortality rates for all causes used the official mortality tables 2012/2014 published by the Portuguese National Statistics Institute. ${ }^{15}$

Table 1 resumes the main epidemiologic parameters used in base case scenario.

\section{Efficacy of PCV13}

The vaccine's initial efficacy against PD (97.4\%) was considered to be that reported in the randomized, double-blind trial by Black et $\mathrm{al}^{17}$ conducted in 37,868 children at 23 medical centers within Northern California. ${ }^{17}$ Protection is assumed to decrease $2 \%$ per year, in line with other authors. ${ }^{19,20}$ In Portugal, PCV13 covers $51.9 \%$ (2012-2014) and 59\% (2009-2011) of the pneumococcal serotypes causing invasive disease in children and adults, respectively. ${ }^{4,16}$ Vaccine effectiveness against all-cause AOM in children $0-4$ years of age was computed as the average of the estimate by Diel et $\mathrm{al}^{21}$ for Germany and the estimate by Lau et $\mathrm{al}^{20}$ for the United Kingdom, yielding an overall 26.9\% effectiveness.

The herd effect in Portugal was calibrated adapting Waight et $\mathrm{l}^{18}$ trend-adjusted estimates for England and Wales. In particular, the elasticity of adults' PD incidence reduction because of children's vaccination took into account the countries' differences in vaccine coverage. Estimated reductions in adults' incidence associated with 
TABLE 1. Epidemiologic Indices

\begin{tabular}{|c|c|c|c|c|c|c|c|}
\hline Parameter & $0-12 \mathrm{mo}$ & $1-2 \mathrm{yr}$ & $2-5 \mathrm{yr}$ & $5-18 \mathrm{yr}$ & $18-44 \mathrm{yr}$ & $45-64 \mathrm{yr}$ & $65+\mathrm{yr}$ \\
\hline \multicolumn{8}{|l|}{ Incidence rate for 100,000 persons } \\
\hline Crude incidence rate IPD (A1) & $13.64^{*}$ & $7.21^{*}$ & $4.37 *$ & $0.49^{*}$ & $1.45 \dagger$ & $2.33 \dagger$ & $4.51 \dagger$ \\
\hline Crude incidence rate pneumonia $(\mathrm{A} 2) \dagger$ & 72.52 & 72.52 & 72.52 & 72.52 & 17.08 & 48.17 & 305.65 \\
\hline Vaccination coverage $(\mathrm{B}, \%) \ddagger$ & 60.8 & 60.8 & 60.8 & 60.8 & 0.6 & 0.6 & 0.6 \\
\hline Serotype coverage $(\mathrm{C}, \%)$ & $51.9 *$ & $51.9 *$ & $51.9 *$ & $51.9^{*}$ & $59 \S$ & $59 \S$ & $59 \S$ \\
\hline Initial efficacy $(\mathrm{D}, \%) \mathrm{I}$ & 97.4 & 97.4 & 97.4 & 97.4 & 97.4 & 97.4 & 97.4 \\
\hline Herd effect $(\mathrm{E}, \%) \|$ & NA & NA & NA & NA & 23.6 & 19.2 & 13.7 \\
\hline Correction factor $(\mathrm{F})$ & $1.44^{* *}$ & $1.44^{* *}$ & $1.44^{* *}$ & $1.44 * *$ & $1.31 \dagger \dagger$ & $1.24 \dagger \dagger$ & $1.16 \dagger \dagger$ \\
\hline Incidence rate IPD in nonvaccinated population (F1) & 19.69 & 10.41 & 6.31 & 0.71 & 1.90 & 2.89 & 5.24 \\
\hline Incidence rate $\mathrm{CAP}$ inpatients in nonvaccinated population ( $\mathrm{F} 2)$ & 104.71 & 104.71 & 104.71 & 104.71 & 22.42 & 59.77 & 355.20 \\
\hline \multicolumn{8}{|l|}{ Fatality rate for 100,000 persons } \\
\hline $\operatorname{IPD}(\%)$ & $1.70^{*}$ & $1.70^{*}$ & $1.70^{*}$ & $1.70 *$ & $2.86 \dagger$ & $9.88 \dagger$ & $27.94 \dagger$ \\
\hline CAP inpatient (\%) & $1.70^{*}$ & $1.70^{*}$ & $1.70^{*}$ & $1.70 *$ & $1.85 \dagger$ & $5.22 \dagger$ & $12.88 \dagger$ \\
\hline
\end{tabular}

*Grupo de Estudo da Doença Invasiva Pneumocócica da Sociedade de Infeciologia Pediátrica (GEDIP), 2015.

$\doteqdot$ DRG, $2014 .^{12}$

†Pfizer, 2016.

\$Horacio et $\mathrm{al}^{16}(2013)$

IIBlack et $\mathrm{al}^{17}(2000)$.

|Waight et $\mathrm{al}^{18}(2013)$ and authors' estimations.

**Formula: $F=1 /[1-(B \times C \times D)]$.

†Formula: $F=1 /[1-(B \times C \times D)] \times(1+E)$.

CAP indicates community acquired pneumonia; IPD, invasive pneumoccocal disease; NA, not applicable.

children vaccination were $23.59 \%, 19.15 \%$ and $13.68 \%$ for the age groups $18-44,45-64$ and $65+$ years, respectively.

\section{Cost Estimates}

Inpatient, outpatient and indirect costs were included in the analysis. Inpatient costs by age group were estimated using the DRG database, ${ }^{12}$ after identifying episodes whose main diagnosis was PD. Unit costs were based on official tariffs listed in the Portuguese order no. 234/2015. Outpatient resource use was based on the opinions of a panel of experts, and unitary costs were also based on official tariffs. The cost estimates included physician visits, exams, tests and drugs, including the vaccine. Because the administration of PCV13 in children occurs in concomitance with other vaccinations in the National Vaccination Plan, no incremental administration cost was considered in the base case scenario. Drug costs (including vaccination costs) were taken from INFOMED, the drug database from the INFARMED. ${ }^{22}$

The indirect costs included were the losses of productivity for employed parents or adult patients. The indirect cost per lost workday was computed using the average wage in official labor market statis$\operatorname{tics}^{23}$ and adjusted for the employment rate as reported in the employment survey of the second trimester of $2015 .{ }^{24}$ Average daily gross earnings (including social security employer contributions) for both genders were $€ 27.9(\$ 30.4){ }^{2}$ Cost estimates are summarized in Table $2 .{ }^{25,26}$

TABLE 2. Direct and Indirect Cost Estimates (Per Episode)

\begin{tabular}{|c|c|c|c|c|c|c|c|}
\hline Parameter & Sepsis & Bacteremia & Meningitis & Meningitis Sequelae & Pneumonia Inpatients & Pneumonia Outpatients & $\mathrm{AOM}$ \\
\hline \multicolumn{8}{|l|}{ Child episode } \\
\hline $\begin{array}{l}\text { Inpatient } \\
\quad \text { costs }^{*}(€)\end{array}$ & 1160 & 1113 & 4873 & NA & 1160 & NA & $567 \dagger$ \\
\hline Outpatient costs $\doteqdot(€)$ & 91 & 91 & 72 & NA & 45 & 122 & 85 \\
\hline Average hospital LOS* (d) & 11 & 5 & 22 & NA & 6 & NA & NA \\
\hline Parent's absenteeism (d) & $23 \S$ & $9 \S$ & $44 \S$ & 289 & $13 \S$ & $7 \|$ & $3^{* *}$ \\
\hline Average parent's daily salary $\dagger \dagger$ & 22 & 22 & 22 & 22 & 22 & 22 & 22 \\
\hline Indirect costs $(€)$ & 500 & 199 & 971 & 618 & 281 & 155 & 57 \\
\hline \multicolumn{8}{|l|}{ Adult episode } \\
\hline Inpatient costs* $(€)$ & 6476 & 2330 & 7324 & NA & 2143 & NA & NA \\
\hline Outpatient costs $\ddagger(€)$ & 91 & 91 & 91 & NA & 98 & 137 & NA \\
\hline Average hospital LOS* (d) & 16 & NAt+ & 20 & NA & 11 & NA & NA \\
\hline Parent's absenteeism d $\S \S$ & 25 & NAt+ & 29 & NA & 16 & 7 & NA \\
\hline Average parent's daily salary & 28II & 28 II & 28खा & $22+\dagger$ & 28গा & $28 \llbracket \mathbb{I}$ & 28गा \\
\hline Indirect costs $(€)$ & 687 & 189 & 816 & $4031 \|$ & 449 & 195 & NA \\
\hline
\end{tabular}

*2014 DRG database. ${ }^{12}$

$\dagger$ Applied only to the percentage of hospitalized cases estimated at $0.13 \%$.

†xpert opinion for resource consumption, order no. 234/2015 for unitary costs of physician visits, complementary diagnostic procedures and treatment; INFARMED drug database (INFOMED) for drug acquisition costs. ${ }^{22}$

§Assumed 2 times the average hospital length of stay observed in 2014 DRG database. ${ }^{12}$

IIAssumption of 4 weeks of yearly absenteeism.

AAssumed 7 days per episode. ${ }^{25}$

** Speets et al., 2011. ${ }^{24}$

†Assumed conservatively to be equal to female average daily gross earnings.

+ Zero incidence of bacteremia in adult population were found.

$\S \S$ Assumed 1.5 times the hospitalization time observed in 2014 DRG database. ${ }^{12}$

IIIIAverage population salary. ${ }^{23,24}$

|Productivity loss, because of extra 50\% unemployment for people with disabled population. ${ }^{26}$ 
TABLE 3. Results for the Base Case Scenario (Discounted)

\begin{tabular}{|c|c|c|c|}
\hline Parameter & PCV13 & No Vaccine & $\begin{array}{c}\text { Difference } \\
\text { (PCV13 - No Vaccine) }\end{array}$ \\
\hline \multicolumn{4}{|l|}{ Effectiveness } \\
\hline Infections* & 25,173 & 30,899 & -5726 \\
\hline Death from PD* & 775 & 904 & -130 \\
\hline Life yr lost & 8136 & 9545 & -1409 \\
\hline \multicolumn{4}{|l|}{ Costs $(€)$} \\
\hline Vaccination costs & $10,429,984$ & 0 & $10,429,984$ \\
\hline Sequelae direct costs & 5432 & 9509 & -4077 \\
\hline Other direct medical costs & $28,138,930$ & $35,379,949$ & $-7,241,019$ \\
\hline Sequelae indirect costs & $6,204,207$ & $7,427,495$ & $-1,223,289$ \\
\hline Other indirect costs & $6,104,652$ & $8,463,468$ & $-2,358,816$ \\
\hline Total costs & $50,883,204$ & $51,280,421$ & $-397,217$ \\
\hline Net benefit of PCV13 vs. no vaccination $\dagger(€)$ & $28,585,482$ & & \\
\hline
\end{tabular}

\section{RESULTS}

The results were presented for the Portuguese cohort of newborns in 2014 (82,367 children). Costs and benefits associated to the vaccine-positive externality in adults are included in the base case scenario. Results are presented in terms of averted infections, averted deaths from PD, LYG, net benefit in terms of LYG [considering a willingness to pay $€ 20,000(\$ 21,800)$ per LYG] and incremental cost-effectiveness ratios, when applicable.

In the base case scenario, over a lifetime horizon, PCV13 averted 5726 infections (excluding AOM) and 130 deaths from PD when compared with the "no vaccination" strategy. PCV13 was associated with an increase in life years (total LYG of 1409) and with lower overall costs [total savings amount of $€ 397,217$ $(\$ 432,967)]$. In other words, and for the base case scenario, PCV13 was dominant (higher health gains and lower costs) when compared with "no vaccination" with net benefits above $€ 28$ million $(\$ 30$ million), where net benefits are equal to cost savings plus the value of health gains in terms of LYG.

Table 3 shows the main results for the base case scenario.

To assess the robustness of these results in relation to the assumptions made in the base case scenario, univariate sensitivity analyses were performed. In these analyses, the parameters more prone to uncertainty were varied. In particular, we considered scenarios where (1) the annual efficacy of the vaccine declines at a rate of $5 \%$ per year instead of $2 \%$ to account for the possibility of higher decrease of PCV13 effectiveness over time; (2) there is no herd effect; (3) the herd effect in the population $65+$ years of age is halved; (4) there are no costs associated to sequelae; (5) a positive vaccine administration cost is considered; (6) the vaccination scheme is $3+1$ instead of $2+1$; (7) the $97 \%$ efficacy rate reported by Black et a ${ }^{17}$ is replaced by $75 \%$, the lowest effectiveness rate reported in the literature ${ }^{19,27-29}$ and (8) the serotype coverage is proportionally $30 \%$ lower than in the base case scenario. In addition, sensitivity analyses also included scenarios recommended by INFARMED economic evaluation guidelines,${ }^{10}$ in particular exclusion of indirect costs and setting the discount rate at $0 \%$ and $3 \%$ (Table 4 ; scenarios 9,10 and 11 , respectively). In all sensitivity analyses, net benefit for vaccination was positive, ranging between $€ 15$ and $€ 52$ million (\$16 and \$57 million), with exception of the scenario where the herd effect was excluded [ $€-3$ million ( $\$-3.3$ million)]. Table 4 shows the main results for the univariate sensitivity analyses.

\section{DISCUSSION}

The main finding of this cost-effectiveness study is that vaccinating all children in Portugal is a dominant strategy compared with the "no vaccination" scenario, resulting in less deaths from PD and gains in terms of life years saved and infections averted, as well as in lower costs. Results suggested a great potential in the reduction of the PD burden, avoiding up to 130 deaths because of PD. Other costeffectiveness studies, conducted in different European settings, have shown that PCV7 (the first PCV protecting against 7 pneumococcal serotypes) was also a better alternative to "no vaccination." $20,30,31$

TABLE 4. Univariate Sensitivity Analysis

\begin{tabular}{|c|c|c|c|c|c|c|c|}
\hline $\mathrm{N}$ & Scenario & $\begin{array}{c}\text { Cost Difference } \\
(€)\end{array}$ & $\begin{array}{c}\text { Averted } \\
\text { Infections }\end{array}$ & $\begin{array}{c}\text { Averted } \\
\text { Deaths }\end{array}$ & Life yr Gained & Net Benefit* $(€)$ & ICER (€/LYG) \\
\hline 0 & Base case & $-397,217$ & 5726 & 130 & 1409 & $28,585,482$ & NA \\
\hline & Annual efficacy decline rate of $5 \%$ & $-15,625$ & 5299 & 125 & 1362 & $27,252,312$ & NA \\
\hline 2 & Exclusion of herd effect & $+4,060,413$ & 1671 & 4 & 50 & $-3,177,644$ & 89,539 \\
\hline 3 & Herd effect in $65+$ population $-50 \%$ & $+1,167,883$ & 4261 & 71 & 834 & $15,504,486$ & 1401 \\
\hline 4 & Exclusion of sequelae & $+830,149$ & 5726 & 130 & 1409 & $27,358,116$ & 589 \\
\hline 5 & Inclusion of vaccine administration cost $\dagger$ & $+517,057$ & 5726 & 130 & 1409 & $27,671,208$ & 367 \\
\hline 6 & Vaccination scheme $3+1$ & $+2,913,889$ & 5726 & 130 & 1409 & $29,158,162$ & 2067 \\
\hline 7 & Effectiveness of PCV13 at $75 \%$ & $+1,150,590$ & 4165 & 96 & 1043 & $19,700,627$ & 1104 \\
\hline 8 & Serotype coverage: proportional reduction of $-30 \%$ & $+1,586,429$ & 3728 & 86 & 938 & $17,164,675$ & 1692 \\
\hline 9 & Exclusion of indirect costs & $+3,184,888$ & 5726 & 130 & 1409 & $25,003,377$ & 2260 \\
\hline & Costs and benefits discount rate $3 \%$ & $-1,078,195$ & 6216 & 137 & 1505 & $31,184,566$ & NA \\
\hline & Costs and benefits discount rate $0 \%$ & $-4,273,582$ & 8791 & 208 & 2419 & $52,656,114$ & NA \\
\hline
\end{tabular}

*Willingness to pay for a life year gained is considered at $€ 20,000$

$\dagger$ Exchange rate: $€ 1=\$ 1.09$. Drug administration costs $€ 3.70$ as in order no. 234/2015 [Diário da República (Portuguese Official Gazette) no. 153/2015, I Series, of 2015-08-07]. ICER indicates incremental cost-effectiveness ratio; NA, not applicable. 
Our results were robust in a set of univariate sensitivity analyses. The worst sensitivity scenario was that excluding the herd effect. However, based on the results from different studies, ${ }^{28,32-35}$ this scenario is highly unlikely because all these studies reported the existence of a herd effect. In our study, the herd effect on adults of vaccinating children was modeled assuming a simple, linear relationship between the incidence rates in children and in adults, which is, according to the literature, a conservative assumption. ${ }^{36}$ The herd effect of children vaccination is not complete, that is, the incidence of PD is different from zero in adult population. It follows that a strategy of $100 \%$ vaccination of children may be considered insufficient to impact the burden of PD in adults, justifying the vaccination with PCV13 also for adults 65 years of age or greater (Prato et $\mathrm{al}^{37}$ and Pilishvili et $\mathrm{a}^{38}$ for further discussion). In the current study, we did not consider the effects of a progressive reduction of the herd effect because of an increasing direct vaccination coverage of the adult population (above the current population rate of $0.6 \%$ ). Nevertheless, in the sensitivity analysis where the indirect effect on adults 65 years of age and older is halved, the children vaccination strategy continues to be a cost-effective strategy.

The model used in this study is a cohort Markov-type model, which is less precise when compared with dynamic models. Despite some limitations, static models need less input of information for calibration and can be characterized as having higher levels of transparency in so far as the causal mechanisms modeled are concerned. $^{40}$

Another drawback of the modeling strategy adopted is that vaccination with PCV13 is assumed to have no impact on the distribution of serotypes (the so-called serotype replacement effect). To assess the robustness of our results in a situation where serotype replacement occurs, we ran an additional sensitivity analysis where the serotype coverage is $30 \%$ lower than in the base case analysis. This serotype coverage reduction is in line with the impact that PCV7 had on the serotype distribution in Portuguese pediatric population after 5 years of its introduction. ${ }^{39}$ The results, in Table 4, show that vaccination with PCV13 remains cost-effective.

A relevant limitation of this study was that some epidemiologic data necessary to calibrate the model, mainly regarding adults, were based on administrative databases such as the DRG database, because no systematic surveillance of IPD in adults exists in Portugal. A further limitation is that the observed incidence rates needed to be adjusted to simulate a scenario where the population was not vaccinated.

The vaccination of children with PCV13 starting in their first year of life is a very cost-effective intervention. The impressive cost-effectiveness properties result in large part from the herd effect of PCV13, that is, from its ability to reduce PD in adults. Therefore, our results support a strong recommendation to vaccinate infants with PCV13, a strategy that is likely to improve the health of the Portuguese population.

\section{REFERENCES}

1. World Health Organization. Weekly epidemiological record. No. 14, 2012;87:129-144.

2. World Health Organization. Immunization, Vaccines and Biologicals. Pneumococcal disease [WHO website]. 2011. Available at: http://www. who.int/immunization/topics/pneumococcal_disease/en/. Accessed March 3, 2016.

3. Russel F, Sanderson C, Temple B, et al. Global review of the distribution of pneumococcal disease by age and region [WHO website]. SAGE meeting, November 8 - November 10, 2011. Available at: http://www.who.int/immunization/sage/6_Russel_review_age_specific_epidemiology_PCV_schedules_session_nov11.pdf. Accessed March 3, 2016.

4. Pneumococcal Disease Study Group from the Pediatric Infectiology Section of Portuguese Society of Pediatrics (SPP). [Invasive pneumococcal disease in Portugal]. Oral Presentation at XIV Jornadas Nacionais de Infeciologia
Pediátrica, Guimarães; June 18 - June 19, 2015. Data on file. Accessed February 12, 2016

5. World Health Organization. Weekly Epidemiological Record. Pneumococcal vaccines: WHO position paper. [WHO website]. 1999. Available at: http:// www.who.int/wer/pdf/1999/wer7423.pdf. Accessed March 4, 2016.

6. Directorate-General of Health. Directorate-General of Health guideline 011/2015 [Directorate-General of Health website]. 2015. Available at: https://www.dgs.pt/directrizes-da-dgs/normas-e-circulares-normativas/ norma-n-0112015-de-23062015.aspx. Accessed March 3, 2016.

7. Directorate-General of Health. Directorate-General of Health guideline 008/2015 [Directorate-General of Health website]. 2015. Available at: https://www.dgs.pt/directrizes-da-dgs/normas-e-circulares-normativas/ norma-n-0082015-de-01062015.aspx. Accessed March 3, 2016.

8. Directorate-General of Health. Directorate-General of Health guideline 012/2015 [Directorate-General of Health website]. 2015. Available at: https:/www.dgs.pt/directrizes-da-dgs/normas-e-circulares-normativas/ norma-n-0122015-de-23062015.aspx. Accessed March 3, 2016.

9. Portuguese National Statistics Institute (PNSI), Annual estimates of resident population 2014- Resident population (No.) by Place of residence (NUTS 2013), Sex and Age group [PNSI website]. 2015. Available at: https://www. ine.pt/xportal/xmain?xpid=INE\&xpgid=ine_indicadores\&contecto=pi\&ind OcorrCod $=0008273 \&$ selTab $=$ tab0\&xlang=en. Accessed May 25, 2015.

10. Silva EA, Pinto CG, Sampaio C, et al. Orientações Metodológicas para Estudos de Avaliação Económica de Medicamentos [Infarmed website]. 1998. Available at: http://www.infarmed.pt/documents/15786/1431404/ Orien_Metodologicas_E AEM_98.pdf/97ecc641-7e57-4dd7-bf454f2e489b6917. Accessed January 11, 2016.

11. Pneumococcal Disease Study Group from the Pediatric Infectiology Section of Portuguese Society of Pediatrics (SPP). [Epidemiologic vigilance of invasive pneumococcal disease]. Oral Presentation at XI Jornadas Nacionais de Infeciologia Pediátrica, Aveiro; May 7 - May 9, 2009. Available at: http://www.spp.pt/UserFiles/file/Protocolos/Doenca_Invasiva_ Pneumococica_2006_2008.pdf. Accessed February 12, 2016.

12. Central Administration of Health System [Administração Central do Sistema de Saúde, ACSS, I.P]. 2015. Data on file. Accessed June 1, 2015.

13. Liese JG, Silfverdal SA, Giaquinto C, et al. Incidence and clinical presentation of acute otitis media in children aged $<6$ years in European medical practices. Epidemiol Infect. 2014;142:1778-1788.

14. Froes F. Community-acquired pneumonia in adults in mainland Portugal: incidence and mortality in hospital inpatients between 1998 and 2000. Rev Port Pneumol. 2003;9:187-194.

15. Portuguese National Statistics Institute (PNSI), Complete Life Table 2012-2014 [PNSI website]. 2015. Available at: https://www.ine.pt/xportal/ xmain? $x$ pid=INE\&xpgid=ine_destaques\&DES TAQUESdest_boui=22467 7917\&DESTAQUESmodo=2. Accessed March 3, 2016.

16. Horácio AN, Diamantino-Miranda J, Aguiar SI, et al; Portuguese Group for the Study of Streptococcal Infections. The majority of adult pneumococcal invasive infections in Portugal are still potentially vaccine preventable in spite of significant declines of serotypes 1 and 5. PLoS One. 2013;8:e73704.

17. Black S, Shinefield H, Fireman B, et al. Efficacy, safety and immunogenicity of heptavalent pneumococcal conjugate vaccine in children. Northern California Kaiser Permanente Vaccine Study Center Group. Pediatr Infect Dis J. 2000;19:187-195.

18. Waight PA, Andrews NJ, Ladhani SN, et al. Effect of the 13-valent pneumococcal conjugate vaccine on invasive pneumococcal disease in England and Wales 4 years after its introduction: an observational cohort study. Lancet Infect Dis. 2015;15:535-543.

19. Andrews NJ, Waight PA, Burbidge P, et al. Serotype-specific effectiveness and correlates of protection for the 13-valent pneumococcal conjugate vaccine: a postlicensure indirect cohort study. Lancet Infect Dis. 2014;14:839846.

20. Lau WC, Murray M, El-Turki A, et al. Impact of pneumococcal conjugate vaccines on childhood otitis media in the United Kingdom. Vaccine. 2015;33:5072-5079.

21. Diel M, Laurenz M, Krause K, et al. Impact of pneumococcal conjugate vaccines on acute otitis media among children in Germany. 31st Annual Meeting of the European Society for Paediatric Infectious Disease; June 1, 2013; Milan.

22. INFARMED. INFOMED Medicines database [Infarmed website]. Available at: http://app7.infarmed.pt/infomed/inicio.php. Accessed April 1, 2015.

23. Office for Strategy and Studies (GEE), Ministry of Economy. Employment Statistical Bulletin May 2015 [GEE website]. 2015. Available at: www.gee. min-economia.pt/?cfl=34856. Accessed May 1, 2016. 
24. Portuguese National Statistics Institute (PNSI). Employment statistics, 2nd trimester 2015, August 2015. Available at: http://www.ine.pt. Accessed February 1, 2016.

25. Speets A, Wolleswinkel J, Cardoso C. Societal costs and burden of otitis media in Portugal. J Multidiscip Healthc. 2011;4:53-62.

26. Organization for Economic Co-operation and Development (OECD). Sickness, Disability and Work Background Paper [OECD website]. 2009. Available at: http://www.oecd.org/dataoecd/42/15/42699911.pdf. Accessed April 1, 2016.

27. van der Linden M, Falkenhorst G, Perniciaro S, et al. Effectiveness of pneumococcal conjugate vaccines (PCV7 and PCV13) against invasive pneumococcal disease among children under two years of age in Germany. PLoS One. 2016;11:e0161257.

28. Moore MR, Link-Gelles R, Schaffner W, et al. Effect of use of 13-valent pneumococcal conjugate vaccine in children on invasive pneumococcal disease in children and adults in the USA: analysis of multisite, populationbased surveillance. Lancet Infect Dis. 2015;15:301-309.

29. Guevara M, Barricarte A, Torroba L, et al; Working Group for Surveillance of the Pneumococcal Invasive Disease in Navarra. Direct, indirect and total effects of 13-valent pneumococcal conjugate vaccination on invasive pneumococcal disease in children in Navarra, Spain, 2001 to 2014: cohort and case-control study. Euro Surveill. 2016;21.

30. McIntosh ED, Conway P, Willingham J, et al. Pneumococcal pneumonia in the UK--how herd immunity affects the cost-effectiveness of 7-valent pneumococcal conjugate vaccine (PCV). Vaccine. 2005;23:1739-1745.

31. Hubben GA, Bos JM, Glynn DM, et al. Enhanced decision support for policy makers using a web interface to health-economic models-illustrated with a cost-effectiveness analysis of nation-wide infant vaccination with the 7-valent pneumococcal conjugate vaccine in the Netherlands. Vaccine. 2007;25:3669-3678.

32. Whitney CG, Farley MM, Hadler J, et al; Active Bacterial Core Surveillance of the Emerging Infections Program Network. Decline in invasive pneumococcal disease after the introduction of protein-polysaccharide conjugate vaccine. $N$ Engl J Med. 2003;348:1737-1746.
33. Miller E, Andrews NJ, Waight PA, et al. Herd immunity and serotype replacement 4 years after seven-valent pneumococcal conjugate vaccination in England and Wales: an observational cohort study. Lancet Infect Dis. 2011;11:760-768

34. Ingels H, Rasmussen J, Andersen PH, et al; Danish Pneumococcal Surveillance Collaboration Group 2009-2010. Impact of pneumococcal vaccination in Denmark during the first 3 years after PCV introduction in the childhood immunization programme. Vaccine. 2012;30:39443950 .

35. Steens A, Bergsaker MA, Aaberge IS, et al. Prompt effect of replacing the 7 -valent pneumococcal conjugate vaccine with the 13 -valent vaccine on the epidemiology of invasive pneumococcal disease in Norway. Vaccine. 2013;31:6232-6238.

36. van Vlaenderen I, van Bellinghen LA, Meier G, et al. An approximation of herd effect due to vaccinating children against seasonal influenza - a potential solution to the incorporation of indirect effects into static models. BMC Infect Dis. 2013;13:25.

37. Prato R, Fortunato F, Martinelli D. Pneumococcal pneumonia prevention among adults: is the herd effect of pneumococcal conjugate vaccination in children as good a way as the active immunization of the elderly? Curr Med Res Opin. 2016;32:543-545.

38. Pilishvili T, Bennett NM. Pneumococcal disease prevention among adults: Strategies for the use of pneumococcal vaccines. Vaccine. 2015;33(suppl 4):D60-D65.

39. Nunes S, Félix S, Valente C, et al. The impact of private use of PCV7 in 2009 and 2010 on serotypes and antimicrobial resistance of Streptococcus pneumoniae carried by young children in Portugal: comparison with data obtained since 1996 generating a 15-year study prior to PCV13 introduction. Vaccine. 2016;34:1648-1656.

40. Pitman R, Fisman D, Zaric GS, et al; ISPOR-SMDM Modeling Good Research Practices Task Force. Dynamic transmission modeling: a report of the ISPOR-SMDM Modeling Good Research Practices Task Force-5. Value Health. 2012;15:828-834. 